\title{
Contribution of integrated teaching in the improvement of an undergraduate ophthalmology curriculum
}

This article was published in the following Dove Press journal:

Advances in Medical Education and Practice

19 November 2014

Number of times this article has been viewed

\section{loannis T Tsinopoulos Chrysanthos Symeonidis Konstantinos T Tsaousis \\ Asimina Mataftsi \\ Nikolaos Chalvatzis \\ Argyrios Tzamalis \\ Lampros $\mathrm{P}$ Lamprogiannis \\ Stavros A Dimitrakos}

2nd Department of Ophthalmology, Medical School, Aristotle University of Thessaloniki, Thessaloniki, Macedonia, Greece
Correspondence: Konstantinos T Tsaousis 2nd Department of Ophthalmology, Medical School, Aristotle University of Thessaloniki, "Papageorgiou" General Hospital, 56429 Thessaloniki, Greece Tel +302310693715

$\mathrm{Fax}+302310693974$

Email konstantinos.tsaousis@gmail.com
Purpose: Conventional medical curriculum is the rule of medical teaching in Greek Medical Schools. Medical students are often taught irrelevant details with little or no reference to their potential clinical significance. Alternatively, integrated teaching warrants that the complete teaching material is covered by each faculty member not considering areas of personal expertise. The aim of this study was to evaluate the implementation of integrated teaching in ophthalmic training.

Methods: The main outcome measures of this retrospective study were a) comments and recommendations made anonymously by the fifth-year medical students in the evaluation questionnaires filled in at the end of their training, and b) scores obtained by students in their final examination at the end of their training in the 2nd Department of Ophthalmology as part of the core Curriculum of the Medical School of the Aristotle University of Thessaloniki. The latter outcome was analyzed with respect to the implementation of integrated teaching.

Results: The score obtained by students in the final examination, which is an objective outcome measure, increased significantly after the implementation of integrated teaching. The final grade (scores out of 10) of students who were trained with the integrated system $(6.17 \pm 1.67$, mean \pm standard deviation) was significantly higher compared to those $(5.52 \pm 2.20)$ trained with the conventional system $(P<0.001)$. The positive outcome of this process was evident as there was a significant increase in the number of students satisfied with the teaching process compared to previous academic years.

Conclusion: Based on the experience of eight academic years and as a result of interactive assessment process our department has modified its medical student teaching process from conventional to integrated; all teaching staff members are involved in the teaching process, while students are divided in small groups. In conclusion, integrated teaching in small student groups appears to be an efficient teaching method (for both theoretical and clinical skills) of ophthalmic training for medical students.

Keywords: medical teaching, integrated teaching, medical training assessment

\section{Introduction}

Medical teaching in the form of a conventional medical curriculum is the rule in Greek Medical Schools. Material relevant to each subspecialty is taught by a corresponding member of the teaching staff in the form of lectures. Limited focus on clinical skills and interaction with patients are some of the inadequacies of this curriculum. This anachronism gives rise to several problems regarding medical teaching. One example is that teaching adequacy is theoretically included in the criteria for academic advancement, but formal evaluation lacks specific assessment tools. Moreover, students do not achieve a comprehensive understanding of any topic taught to them, since there 
is significant diversity of interests, resources, and approaches between several departments responsible for teaching different aspects of a particular topic. Consequently, there is lack of integration in course materials in medical undergraduate teaching. ${ }^{1,2}$ Unfortunately, medical students are often taught irrelevant details with little or no reference to their potential clinical significance. Moreover, clinical relevance of the basic science courses is lost to students at the time of their clinical training as a result of lack of emphasis. Students are led to think that memorization of vast amounts of information is the key to proper education, whereas clinical skills are not considered that important. . $^{3,4}$

During the past two decades, integrated curricula have been commonly employed, mainly due to the basic inadequacy of basic science teaching: no apparent clinical relevance. Conventional teaching methods appeared not able to meet contemporary needs for interdisciplinary pre-clinical and clinical practice. ${ }^{5}$ Vertical integration linking basic science and clinical practice with the use of problem-based learning facilitated increased comprehension of medical principles. ${ }^{6}$ In the limited spectrum of a single specialty, integrated teaching ensures that the entire teaching material is covered by every faculty member regardless of areas of personal expertise and/or research. ${ }^{7}$ There is a considerable focus on clinical skills as they are taught along with the respective theoretical background on the same day. As teaching is done in small groups, the tutor is able to initiate and guide a discussion in order to help students identify and solve a clinical problem. Consequently, there is increased student participation in the acquisition of basic clinical skills. ${ }^{8}$ Learning theories propose that integrated teaching may be beneficial due to its facilitation of contextual learning as well as efficient analysis of clinical problems. ${ }^{9}$

The ophthalmic manifestations of several systemic diseases have rendered the acquisition of basic theoretic and clinical skills in ophthalmology by medical students, a prerequisite in the context of a comprehensive medical training. To our knowledge, the Medical School of the Aristotle University of Thessaloniki is the first medical school in Greece to implement integrated teaching in ophthalmology training for undergraduate medical students.

The aim of our study was to evaluate the implementation of integrated teaching in ophthalmic training with the use of a structured questionnaire completed by medical students as well as comparisons of examination scores following the completion of the respective semesters.

\section{Materials and methods}

Between the academic years 2004/2005 and 2009/2010 (673 students, mean: 112 students/year), conventional teaching was the common practice in our department; every member of the teaching staff taught skills from his/ her area of expertise. During the academic years 2010/2011 and 2012/2013 (247 students, mean: 123 students/year), integrated teaching was employed; every member of the teaching staff covered all clinical skills in small student groups. There was a slight decrease in the number of teachers (range: 8-10) and a small increase in the number of students (112 students/year vs 123 students/year), as well as a minor decrease in the faculty to student ratio (12.8 to 13.9). The small increase in the faculty to student ratio can be attributed to decreased postings during the previous 3 years as a result of the ongoing economic crisis.

In our department, the modification of the curriculum from conventional to integrated teaching took place after eight academic years and following an interactive and impartial assessment process. The transformation of the teaching process, in line with the students' evaluation and criticism and eventually integrated teaching was employed from the academic year 2010/2011. All lectures were replaced by seminars in small student groups. While all supplementary teaching materials (PowerPoint presentations and reading materials regarding theoretical background and clinical skills) were available to all students before every teaching session, students were asked to be prepared for specific theoretical and clinical skills that were to be covered during each session. As a result, time spent on each skill was equally distributed and thus all students received standardized theoretical and clinical training.

The main outcome measures of this retrospective study were the comments and recommendations of the fifth-year medical students in the evaluation questionnaires following their training in the 2nd Department of Ophthalmology as part of the core Curriculum of the Medical School of the Aristotle University of Thessaloniki in addition to comparisons of examination scores following the completion of the respective semesters.

Questionnaires from nine academic years (from 2004/2005 to 2012/2013) were included. Fifth-year students were given 30 minutes to complete an anonymous questionnaire in a hospital amphitheater following their final examinations in order to exclude possible bias during completion.

The questionnaire consisted of ten questions, where students were asked to evaluate particular aspects of their 
training mainly focusing on the sufficiency of ophthalmic training provided for use in general practice (grades: 1-2: unacceptable, 3-4: inadequate, 5-6: adequate, 7-8: good, and 9-10: very good). Questions were grouped regarding access to the hospital and the department in particular, evaluation of training posts, the content of the clinical skills laboratory and the time available for training, the 90 theoretic and 32 clinical skills, the quality of ophthalmology training in preparing medical students for general practice, the adequacy of the clinical skills taught for use in general practice, the Ophthalmology textbook, and the teaching staff. There were also five areas of potential recommendations regarding ophthalmology training in the department (clinical skills laboratories and inpatient examination) as well as in outpatient clinics. The detailed questionnaire remained virtually unchanged throughout the reported period of nine academic years. Since there were a limited number of changes in the faculty of the department, minor questionnaire alterations regarding individual trainer assessment were employed.

At the end of each semester, written examinations were performed, consisting of 28 multiple choice questions with only one correct answer. Clinical skills were also evaluated at the end of each semester with oral examinations in the department prior to written examinations. Theoretical skill examination scores contributed $70 \%$ of the final grade, while clinical skills scores contributed $30 \%$.

Statistic analysis was conducted with the use of the SSPS version 19.0 (SPSS Inc, Chicago, IL, USA) statistical package. Mean values for each question and academic year were calculated. Comparisons between student groups were performed using analysis of variance (ANOVA) and independent samples Student's $t$-test.

\section{Results}

Descriptive statistics regarding the number of medical students trained in the 2nd Department of Ophthalmology, Medical School of the Aristotle University of Thessaloniki, between the academic years 2004/2005 and 2012/2013 as well as teaching method and correct answers in the final examination are depicted in Table 1.

With respect to student evaluation of the curriculum modification, there was a statistically significant difference for both relevant questions (the content of the clinical skills laboratory and the time available for training and the quality of ophthalmology training in preparing medical students for general practice) between 1) years when conventional teaching was employed (2004/2005 till 2009/2010) and 2) the
Table I Medical students trained in the 2nd Department of Ophthalmology, Medical School of the Aristotle University of Thessaloniki between the academic years 2004/2005 and 2012/2013: teaching method, final examination scores, and comparisons between academic years

\begin{tabular}{llll}
\hline $\begin{array}{l}\text { Academic } \\
\text { year }\end{array}$ & $\begin{array}{l}\text { Number of } \\
\text { medical } \\
\text { students }\end{array}$ & $\begin{array}{l}\text { Teaching } \\
\text { method }\end{array}$ & $\begin{array}{l}\text { Final examination } \\
\text { score }^{\text {a }} \text { (mean } \pm \text { SD) }\end{array}$ \\
\hline $2004 / 2005$ & 119 & Conventional & $8.00 \pm 1.63$ \\
$2005 / 2006$ & 116 & Conventional & $6.29 \pm 1.94$ \\
$2006 / 2007$ & 89 & Conventional & $5.96 \pm 1.66$ \\
$2007 / 2008$ & 140 & Conventional & $3.88 \pm 1.90$ \\
$2008 / 2009$ & 113 & Conventional & $4.90 \pm 1.22$ \\
$2009 / 2010$ & 96 & Conventional & $4.83 \pm 1.54$ \\
$2010 / 2011$ & 108 & Integrated & $5.34 \pm 1.48$ \\
$2011 / 2012$ & 139 & Integrated & $6.15 \pm 1.46$ \\
$2012 / 2013$ & 123 & Integrated & $6.89 \pm 1.72$ \\
\hline
\end{tabular}

Note: ${ }^{\text {a Out of } 10 .}$

last 3 years during which integrated teaching was employed (2010/2011, 2011/2012, and 2012/2013) (P<0.05). Students evaluated integrated teaching as a more effective teaching method.

In the recommendations section, students requested increased hours of clinical skills training as well as participation in inpatient examination and outpatient clinics, favoring these activities over theoretical teaching.

With respect to the impact of the curriculum modification to final examination grades, students were divided in to two groups: those who were trained with the conventional system (classes 2005-2009) and those who were trained with the integrated system (classes 2010-2013). Overall, the final grade (scores out of 10) of the students in the second group (6.17 \pm 1.67 , mean \pm standard deviation) was significantly higher compared to those $(5.52 \pm 2.20)$ of the first group $(P<0.001)$. Moreover, comparing the final grade between classes that were trained with the integrated method, a statistically significant increase was observed $(P<0.001$, ANOVA) from the year 2011 onward.

\section{Discussion}

Conventional medical school curricula are often divided into pre-clinical and clinical years. All subjects are taught in the form of lectures by teachers that focus on their area of expertise and research interests. Significant emphasis is sometimes given to specialized topic which are rarely encountered by the majority of doctors in their clinical practice. This approach, which can be characterized as teacher-centered, makes the integration of basic science knowledge with clinical practice 
as well as problem solving considerably challenging for medical students. The inherent disadvantage of this method lies in its lack of association between the separate parts of ophthalmic curriculum for medical students. Differences in teaching styles between members of the teaching staff represent an additional problem. Students are taught parts of the required curriculum from specialists with appropriate subspecialty training. As specialists focus on their individual areas of interest, there is inadequate emphasis on primary care training.

After eight academic years and following an interactive and impartial assessment process, our department has altered its curriculum from conventional to integrated teaching. This transition was in accordance with previous studies that identified factors such as curriculum and examinations as fundamental for undergraduate learning. ${ }^{10,11}$ Seminars in small student groups in lieu of lectures as well as increased student involvement are the basic characteristics of this significant curriculum modification. Since students were required to be prepared for specific theoretical and clinical skills for each session, there was increased student participation in the acquisition of basic clinical skills. Standardized training was achieved by distributing teaching time evenly between theoretical and clinical skills regardless of the tutor's subspecialty.

The impact of this change from conventional to integrated teaching on student grades was considerable as reported in this study. Student grades in their final examination, which is an objective outcome measure, increased significantly after initiating integrated teaching, and this finding has not been previously reported. This could be attributed to increased active student participation as a result of available teaching material and required student preparation before each teaching session. Furthermore, lectures which decreased student participation and attention as well as consumed significant part of the available teaching time were eliminated from the department curriculum. These findings are in agreement with relevant studies; more correct diagnoses were made by students that graduated from an integrated curriculum compared to students from a conventional curriculum. ${ }^{12}$ In this study, student evaluation of their training was employed as a subjective outcome measure. At the end of the corresponding semester, students believed in the adequacy of their ophthalmological training, both theoretical and clinical, an observation arising from their post-training evaluation. Regarding integrated teaching, student satisfaction was expressed as a result of possibility of constant access to a single member of the teaching staff as well as the cohesion and continuity of the clinical skill training that a single member of the teaching staff can provide.

There have been numerous studies addressing the advantages of integrated teaching in medical education. ${ }^{8,10,13,14}$ This study is the first report of its kind, demonstrating the feasibility of employing integrated teaching in a specific specialty prior to its implementation in a medical faculty curriculum. In addition, it covers an extended time-span, and therefore provides solid evidence for the superiority of integrated over conventional teaching. The positive outcome of this process was evident as there was a significant increase in the number of students satisfied with the teaching process compared to previous academic years. Moreover, the superiority of integrated teaching was also demonstrated by the significant increase in student grades in the Ophthalmology final examinations following its implementation in the Ophthalmology curriculum. The next step in this evolutionary process could be the introduction of problem-based learning as a separate feature in the clinical skills section of the ophthalmic curriculum. Other medical schools may also benefit from the implementation of curriculum innovations as well as conclusions reported in the present study. In conclusion, integrated teaching in small student groups appears to be an efficient teaching method (for both theoretical and clinical skills) of ophthalmic training for medical students.

\section{Acknowledgment}

No financial support was received for this submission.

\section{Disclosure}

None of the authors has conflict of interest with the submission.

\section{References}

1. Jonas HS, Etzel SI, Barzansky B. Undergraduate medical education. JAMA. 1989;25(262):1011-1019.

2. Shah M, Knoch D, Waxman E. The state of ophthalmology medical student education in the United States and Canada, 2012 through 2013. Ophthalmology. 2014;121(6):1160-1163.

3. Steedman M, Abouammoh M, Sharma S. Multimedia learning tools for teaching undergraduate ophthalmology: results of a randomized clinical study. Can J Ophthalmol. 2012;47(1):66-71.

4. Li JZ, Chan SC, Au M, et al. Review of a medical student-run surgery lecture series and skills lab curriculum. Can J Surg. 2014;57(3):152-154.

5. Custers E, Ten Cate TJ. Medical students attitude towards and perception of the basic sciences: a comparison between students in the old and new curriculum at the University Medical Centre Utrecht, The Netherlands. Med Educ. 2002;36:1142-1150.

6. Dahle LO, Brynhildsen J, Behrbohm Fallsberg M, Rundquist I, Hammar M. Pros and cons of vertical integration between clinical medicine and basic science within a problem-based undergraduate medical curriculum: examples and experiences from Linkoping, Sweden. Med Teach. 2002;24(3):280-285. 
7. Rao KH, Rao RH. Perspectives in medical education 5. Implementing a more integrated, interactive and interesting curriculum to improve Japanese medical education. Keio J Med. 2007;56:75-84.

8. Shimura T, Aramaki T, Shimizu K, Miyashita T, Adachi K, Teramoto A. Implementation of integrated medical curriculum in Japanese medical schools. J Nippon Med Sch. 2004;71:11-16.

9. Regehr G, Norman G. Issues in cognitive psychology: implications for professional education. Acad Med. 1996;96:988-1002.

10. Davis J, Chryssafidou E, Zamora J, Davies D, Khan K, Coomarasamy A. Computer-based teaching is as good as face to face lecture-based teaching of evidence based medicine: a randomised controlled trial. BMC Med Educ. 2007; 7:23.
11. Karthikeyan K, Kumar A. Integrated modular teaching in dermatology for undergraduate students: a novel approach. Indian Dermatol Online J. 2014;5(3):266-270.

12. Schmidt HG, Machiels-Bongaerts M, Hermans H, ten Cate TJ, Venekamp $\mathrm{R}$, Boshuizen HP. The development of diagnostic competence: comparison of a problem-based, an integrated, and a conventional medical curriculum. Acad Med. 1996;71:658-664.

13. Lam FC, Lim LT, Dutton GN. Short sessions of intensive structured teaching: an effective form of undergraduate ophthalmology teaching? Med Teach. 2011;33(11):950.

14. Li JZ, Chan SC, Au M, et al. Review of a medical student-run surgery lecture series and skills lab curriculum. Can J Surg. 2014;57(3):152-154.

\section{Publish your work in this journal}

Advances in Medical Education and Practice is an international, peerreviewed, open access journal that aims to present and publish research on Medical Education covering medical, dental, nursing and allied health care professional education. The journal covers undergraduate education, postgraduate training and continuing medical education including emerging trends and innovative models linking education, research, and health care services. The manuscript management system is completely online and includes a very quick and fair peer-review system. Visit http://www.dovepress.com/testimonials.php to read real quotes from published authors.

Submit your manuscript here: http://www.dovepress.com/advances-in-medical-education-and-practice-journal 